\title{
TRANSPORT ENERGY AND EMISSIONS AND THEIR RELATION TO ECONOMIC OUTPUT
}

\author{
Zdeněk ŘíHA ${ }^{1}$, Marek HONCÜ ${ }^{2}$ \\ ${ }^{1}$ Department of Economics and Management of Transport and Telecommunications, Faculty of Transportation Sciences, \\ Czech Technical University in Prague, Czech Republic. E-mail: riha@ fd.cvut.cz \\ ${ }^{2}$ Department of Economics and Management of Transport and Telecommunications, Faculty of Transportation Sciences, \\ Czech Technical University in Prague, Czech Republic.
}

Accepted 15 October, 2011

\begin{abstract}
The transport system has big influence on national economy as well as on environment and life quality. The modern economy with high level of labour division would not be productive enough without efficient transport systems. However, they require increasing transport capacity and have higher impact on the environment and power supply. It is a proved fact, that countries with more liberal economy are economically stronger (the relation between the index of economic freedom and the gross domestic product). But the question is what the consequences for other human activities are and whether in the transportation we can use the so called Kuznets curve, which predicates that the environmental impacts decrease with the increasing wealth. We particularly examine the relationship between total amount of exhaust emissions from road transport in the Czech Republic and other European countries and their economic wealth expressed as the GDP per capita. This relation is known as the Kuznets environmental curve and it claims that from a certain level of welfare the total human impacts on the environment decrease.
\end{abstract}

Keyword: emissions, energy, environmental Kuznets curve, externality, GDP, transport.

\section{INTRODUCTION}

The transportation has been during the history of mankind the basic driver of the human society development. It has determined not only the location of towns, but also their internal form and last but not least it was the basic element of the economic development as the inevitable presumption of the goods barter.

The close relationship between transportation and national economy can be demonstrated during the centuries of human existence by plenty of examples. Transport is one of the basic elements of trade (i.e. barter of goods) and besides natural resources or human capital the next important source of the wealth of societies that follows from the simple law of comparative advantages.

The Figure1 shows how countries can move from one consumption possibilities curve to another one, when they use the bilateral trade and so they utilize from the division of labour.

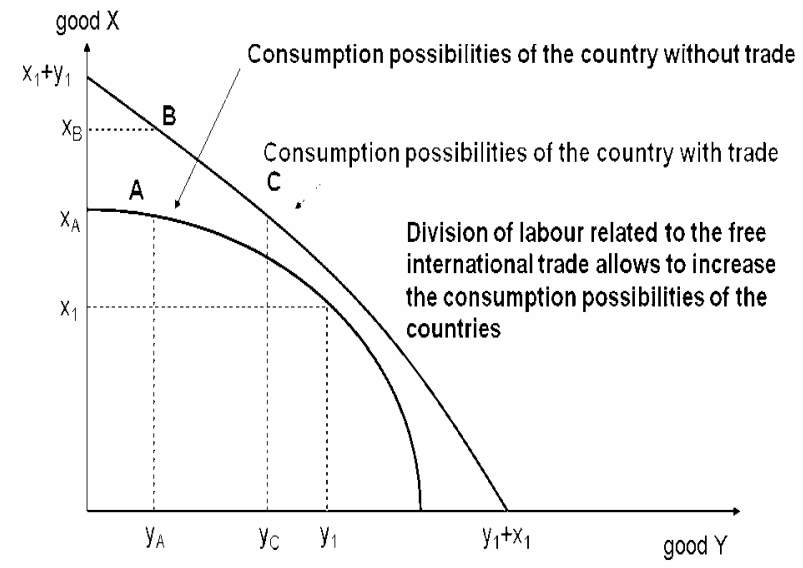

Figure 1: Principle of comparative advantages

This principle helped in the past many countries to gain wealth and it is helps (what is of course true not only for the national economies, but for individuals or firms). So the ancient China could enjoy prosperity at the time of existence of the Silk trail as well as the states around the Mediterranean Sea that could use the maritime transport for their trade. The railway connecting the East with the West of the USA fastened the colonization of its 
area. Today this mutual dependence is also large and it has been used by still more countries since the time of the industrial revolution, that made possible to build the infrastructure essentially independently of natural disposals.

The principle of the industrial revolution, consisting of the higher use of the division of labour, was already described in the second half of the $18^{\text {th }}$ century by the Scottish economist Adam Smith $(1723$ - 1790) in his famous book "An Inquiry into the Nature and Causes of the Wealth of Nations" (Smith, 2002). The division of labour increases the output of the economy, so the higher is the degree of the division of labour, the more is the need of a high efficient transport system. This is why during the Medieval Ages the countries with access to sea were richer, because they could use for trade the then dominating water transport. By the way, that is why Adam Smith was opponent of all state interventions, limiting the free trade among states.

\section{ECONOMIC FREEDOM AND GDP}

The possibility to barter free is also one of the factors influencing the so called index of economic freedom (IEF), published by the Heritage Foundation. This index comprises i.e. especially the freedom of trade, but also the range of the state sector or the observance of the human rights. It results explicitly from the various data compared with the GDP of respective countries, that the greater is the economic freedom measured by the IEF index, the higher is also the gross domestic product of the countries.

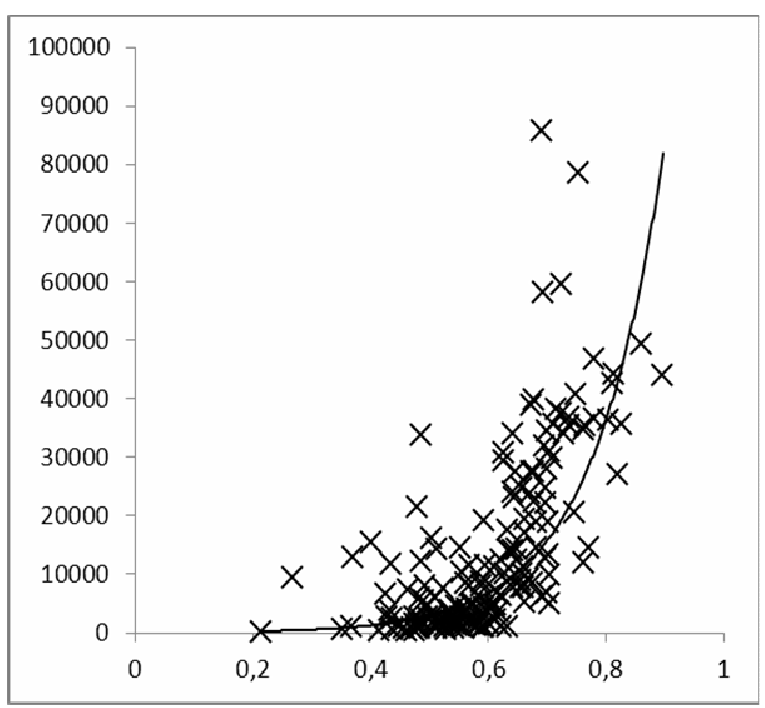

Figure 2: The relation between the index of economic freedom IEF and the gross domestic product [thousands US\$]

(source: www.heritagefoundation.com)
The higher GDP needs greater economic freedom. And probably this always used to be so in the history. Another problem is how the economic growth influences other parameters, mainly the environment.

\section{GDP AND TRANSPORTATION}

As for the road transport, it is especially interesting to follow the relation of the GDP and the development of the individual motoring that has the largest environmental impacts. By the comparison of the particular countries we can find the relation between passenger car transport output in the EU countries and GDP per capita, as shown in Figure 3.

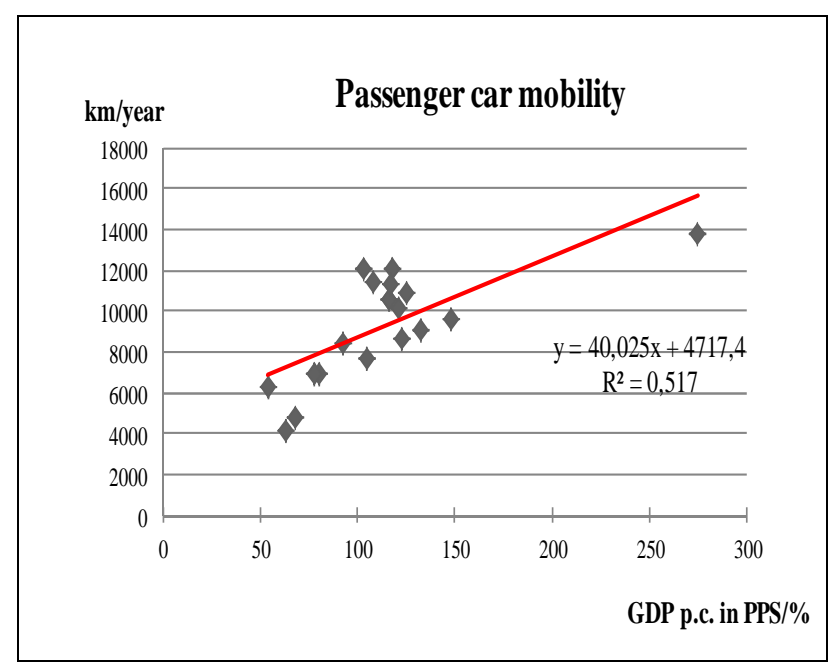

Figure 3: The relation between the GDP per capita and the individual car transport output of the EU countries.

(source: Czech Statistical Office)

The graph in Figure 3 shows that the higher is the GDP, the larger is also the output of the individual car transport. It is interesting that the points mostly left belong to the Czech Republic, Poland, Hungary and Slovakia. On the contrary, the point mostly right represents Luxembourg. So we come to the paradox that the economic freedom leads to the growth of the level of living, but it can have larger impacts on the environment. But does that really hold true? In fact the 20th century brought the crucial question, whether the impacts of human activities on the environment are so serious, that it is necessary to control them by some way. If we consider only the transport, there are at least two broadly accepted reasons to make control:

The environmental reason - the total impacts of transportation on the natural environment and the human health are continually higher, above all in cities. These consequences have mostly the form of external costs and are the 
main reason for the higher transport regulation

- $\quad$ The energetic reason - the problems with oil and other resources and their geographic distribution and above all the security of oil (or natural gas) supply from the countries with non-liberal or even less or more dictator regimes have led to the need to seek for the energy security and to the development of new possibilities of car propulsion

The mankind has never been resolving such situation (we do not want to claim, that the mankind did not resolve lots of problems and challenges in its history, only the character of this situation is different). On the one hand, the level of living standard increased markedly in the more advanced (simply said the north one) part of the world, for what there are surely many reasons; however one of them is the human possibility to use the energy from fossil fuels. But it has impacts on the environment (apart from the greenhouse effect and the global warming like about demonstrable local impacts of the transport on the environment and the human health in cities) and moreover, fossil fuels are exhaustible resources.

\section{TRANSPORT AND LIFE QUALITY}

The transport system also substantially affects life quality, especially in towns. Life quality is of course a very questionable concept, due to many factors (partly highly subjective), affecting, finally, the resulting life quality. From many approaches and models we can demonstrate the complexity of the problem on the approach of Ruut Veenhoven (2000) that divided the life quality on inner and outer one and classified this concept according the following Table 1 .

Table 1: The four qualities of life (Veenhoven, 2000)

\begin{tabular}{|c|c|c|}
\hline $\begin{array}{c}4 \text { Qualities } \\
\text { of Life }\end{array}$ & $\begin{array}{c}\text { Outer } \\
\text { Qualities }\end{array}$ & $\begin{array}{c}\text { Inner } \\
\text { Qualities }\end{array}$ \\
\hline Life chances & $\begin{array}{l}\text { Life ability of } \\
\text { environment }\end{array}$ & $\begin{array}{l}\text { Life-ability of } \\
\text { the person }\end{array}$ \\
\hline Life results & Utility of life & Appreciation of life \\
\hline
\end{tabular}

From the indicated approach it unambiguously follows (and other models would confirm it) that the influence of economic factors and other hard ones will be limited and the life quality will be affected by many other, subjective impacts. From the viewpoint of the transport system the link to the first quadrant will be interesting - thus how the transport system influences the environment that afterwards affects the life quality. The externalities will have a significant influence, whether the negative or positive ones. The relation between the output of the transport system and gross domestic product will be also important.

A separate problem will be also the influence of the quality of the actual transport process. If we consider the transport system as a whole (transport quality is usually associated only with public transport), we can also distinct the inner quality that is a set of constituent quality factors, i.e. accessibility, accuracy, comfort, information availability etc. and that can be expressed by the resulting utility of a passenger. This inner quality will be limited by the GDP indicator that influences the living standard and indirectly the quality of transport means and infrastructure. As outer quality we will call the influence of the transport system on its neighborhood and thus also on its indirect users. This influence is represented by externalities. This relationship can be represented in a simplified way by the scheme in Figure 4.

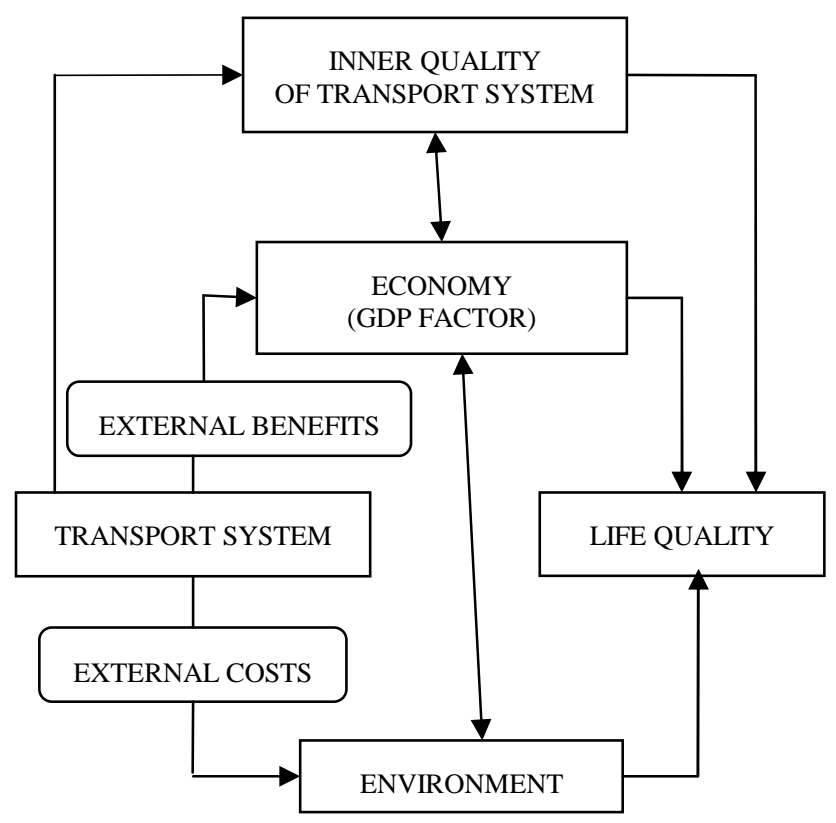

Figure 4: Relation between transport system and life quality

\section{TRANSPORT AND ENERGY}

The world of economics has been facing the increase in crude oil and nature gas prices, see Figure 5. The primary resources of energy, both oil and nature gas, represent an essential raw material not only for energy and transport systems, they also have the large deal for the development of other industrial branches. In contrast to the previous 
crises, we have met certain opinions and predictions about the termination of cheap oil period. It might seem that higher prices have been signaling the lack of oil and nature gas, although this could be false information. Combined impact of the supply and demand is in question as well as the problem of exhaustion of the above mentioned resources and the competitiveness of alternative resources, geological and geographical conditions, reliability of the supplies and, last but not least, the political, social and terrorist aspects.

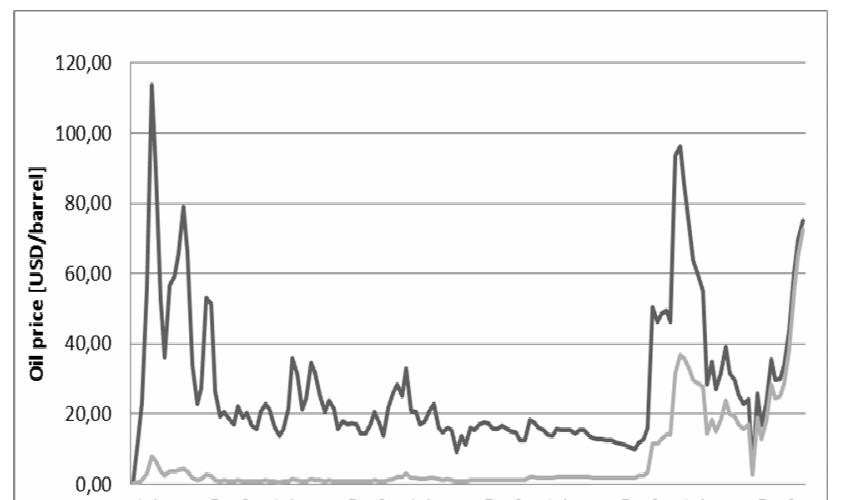


century. They are connected mostly with the name of American economist Kuznets (1955).

Simon Kuznets was an American economist of Russian origin, who was interested in the measuring of the GDP and its relationships to other quantities. The Kuznets curve tells that the higher is the GDP, the smaller are the social differences (we can see it in the developed states with the strong middle class many people earn the average wage level).

\section{ENVIRONMENTAL KUZNETS CURVE}

The derived environmental Kuznets curve (EKC) in not any more his own work, but the construction of the economists Grossman and Krueger (1995). It shows that with the increasing wealth of a country, measured by the GDP, the environment also improves, because for the countries it is profitable to use cleaner technologies only after gaining some level of living. Against this statement the logical objection holds, that countries after gaining certain wealth transfer the production to less developed countries with cheaper labour force. Hence, with the production transfer the related emissions are also transferred. But this proposition is not interesting for our research, because we are concerned with the transportation and its outputs cannot be transferred elsewhere, they always take place in the given country. The general shape of the EKC is shown in Figure 6.

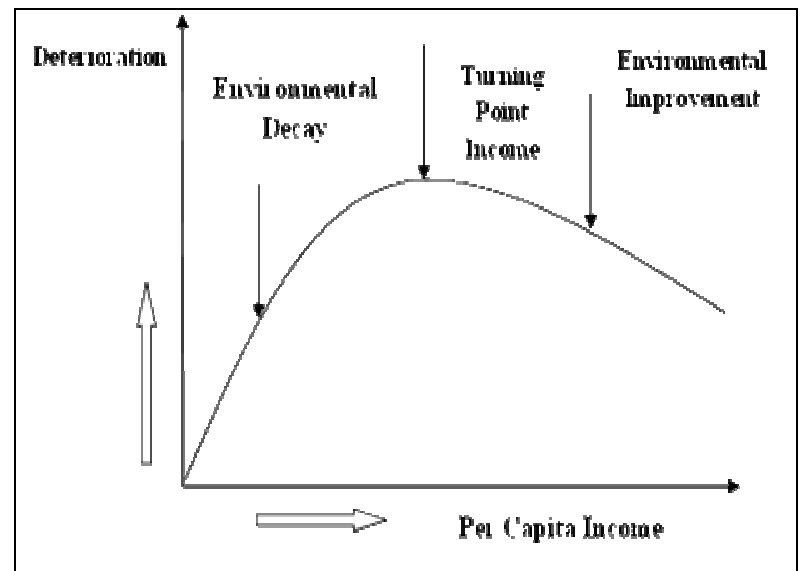

Figure 6: Environmental Kuznets curve (Bhattarai et al., 2004)

Such functions can be modeled by a polynomial of maximum third degree in the linear regression equation

$$
z_{i t}=\beta_{0}+\beta_{1} y_{i t}+\beta_{2} y_{i t}^{2}+\beta_{3} y_{i t}^{3}+\varepsilon_{i t}
$$

where:

$z_{i t} \quad$ - emissions per capita in locality $i$ at time $t$, $\beta_{i} \quad$ - regression coefficients

$y_{i t} \quad$ - average GDP per capita, independent variable and

$\varepsilon_{i t} \quad$ - error term.

The values of parameters $\beta$ influence the shape of the EKC according to the following graphs in Figs. 7 and 8.

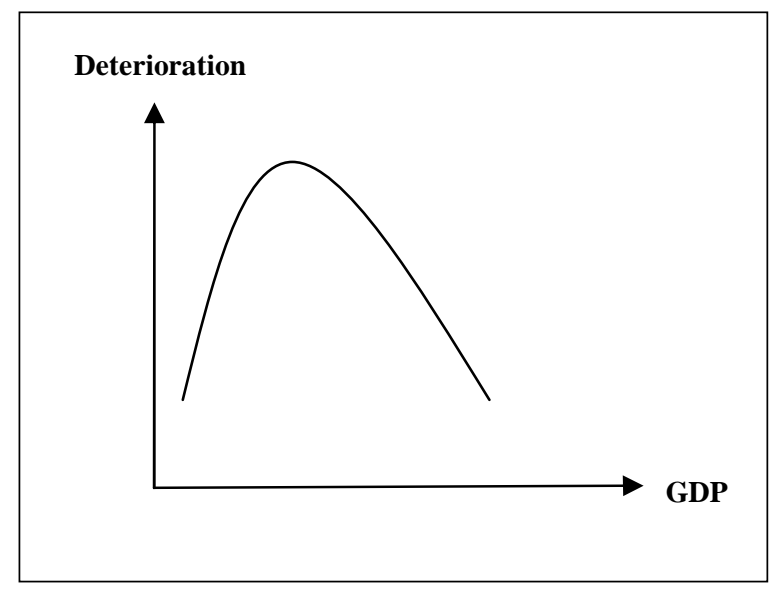

Figure 7: EKC with coefficients $\beta_{1}>0, \beta_{2}<0, \beta_{3}=0$

If $\beta_{3}>0$, the EKC can have the shape as shown in Figure 8. It means that after a phase of decrease the deterioration starts to increase again.

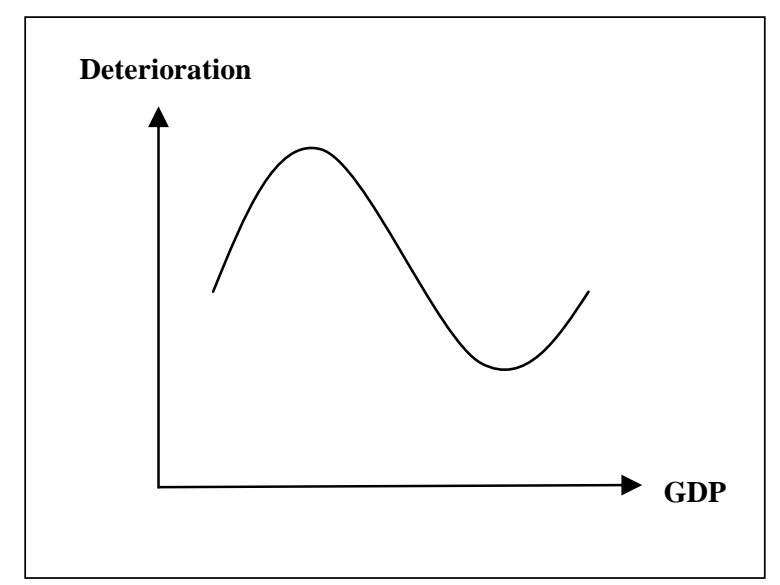

Figure 8: EKC with coefficients $\beta_{3}>0, \beta_{2}{ }^{2}>3 \beta_{1} . \beta_{3}$

Various empirical studies verify the applicability of the EKC (Duchoň, 2010), but it is necessary to interpret this dependence and to look for the reasons why the environmental deterioration decreases with the economic growth. These reasons can be divided into 5 groups:

- The transition from agricultural character of the society to the industrial one during the industrial revolution was followed by the increased environmental deterioration. This is the explanation of the growing part of the EKC. This development can be today 
observed in the developing countries like China and India.

- The decreasing shape of the EKC can be explained by technological changes. Innovation has usually decreased energy consumption rate as well as emission factors of vehicles.

- $\quad$ The demand for better environment has been increasing with the growing wealth. People whose basic needs were satisfied (Maslow's pyramid) have been increasing the pressure on producers to get environmentally cleaner products.

- More wealthy society has been asserting through its public representatives more strict environmental legislation and incentives (of economic character, i. e. consumption and environmental taxes etc.)towards less harmful environment.

- The last reason relates to the transfer of production to poorer countries with lower labor cost, more wealthy countries have been concentrating on the production of services that damage the environment less. This is of course only the case of a local transfer among countries that does not decrease the total environmental damage.

\section{EKC IN ROAD TRANSPORT IN THE CZECH REPUBLIC}

The history of the Czech Republic is not so long yet for us to make far-going conclusions. Nevertheless, we tried to show the relation of the emission from transport on the GDP amount (in current prices), what is included in the following graphs, where the carbon dioxide and nitrogen oxides were chosen as emission examples, see Figures 9 and 10.

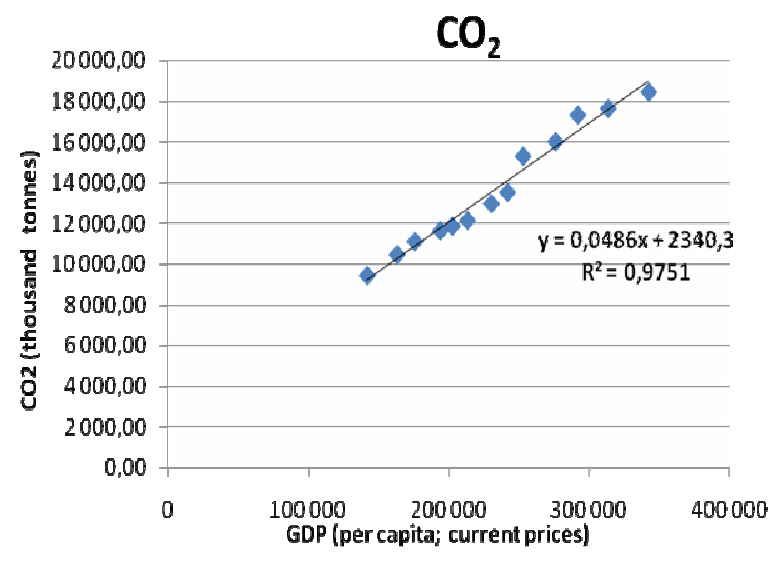

Figure 9: Road transport $\mathrm{CO}_{2}$ emissions in the Czech Republic as function of GDP per capita. (source Czech Statistical Office)

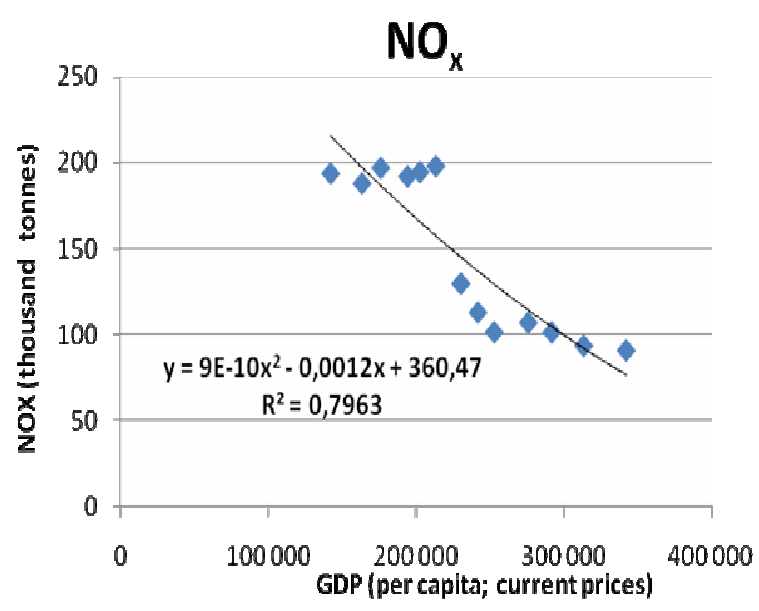

Figure 10: Road transport $N O_{x}$ emissions in the Czech Republic as function of GDP per capita. (source Czech Statistical Office)

The performed analysis shows that the Kuznets environmental curve holds true for some types of emissions form transport in the Czech Republic. Definitely we can say that it is not true for the emissions of the carbon dioxide that have been growing dizzily. But its impacts are still controversial and so it is surprising, that many regulations still relate to this type of emissions. It is of course questionable, whether the Kuznets curve must hold true exactly for this type of emissions.

The production of the greenhouse effect with the essential contribution of the carbon dioxide and the factors influencing the carbon dioxide emissions can be expressed in the macroeconomic equation:

$$
\mathrm{CO}_{2}=\mathrm{POP} \cdot h \cdot e n \cdot e \mathrm{CO}_{2}
$$

where

$\mathrm{CO}_{2}$ - amount of carbon dioxide emissions,

$P O P$ - population; $h$... GDP per capita,

en - energy intensity of the economic system,

$e \mathrm{CO}_{2}$ - amount of carbon dioxide on the unit of energy carrier (carbon intensity).

It follows from the equation (3) that the emissions grow with the population growth, with the economic growth, with the high energy set out of the economy and with the high portion of the fuels with high carbon content on the produced energy unit. The high content of carbon leads to high carbon dioxide emissions. The population and economic growth will be followed by the growth of emissions.

The emissions can be reduced by:

- $\quad$ the cut down of the energy intensity

- the cut down of the carbon intensity 
To decrease the carbon intensity means to move from the fossil fuels to fuels with low or no carbon content.

\section{EKC IN EUROPEAN ROAD TRANSPORT}

For the broader verification of the EKC in road transport we have analyzed the emissions as function of the GDP of 16 countries of the European Union (Bulgaria, Czech Republic, Slovakia, Slovenia, Hungary, Estonia, Lithuania, Latvia, Belgium, France, Germany, Netherlands, Portugal, Austria, Sweden and UK). The emissions are averaged (per capita) in population for the purpose of comparison and the use of data from various countries.

Carbon dioxide emissions show in general (regardless the source activity) a strong linear correlation with GDP (Kuznets, 1955; Grossman and Krueger, 1995). Some authors state that the EKC concept may be inappropriate to describe the relationship between economic growth and carbon dioxide emissions (Bhattarai et al., 2004). The reason can be that carbon dioxide has been considered as a pollutant recently in connection with the problems of global warming.

In the road transport, the emissions of the carbon dioxide also show an almost linear growth with GDP per capita (Duchoň, 2010), as shown in Figure 11.

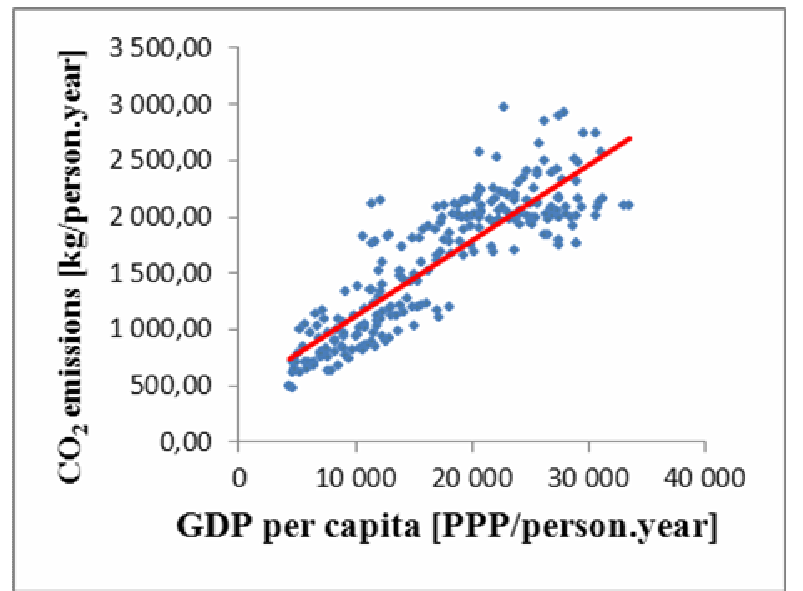

Figure 11: Road transport $\mathrm{CO}_{2}$ emissions as function of GDP per capita.

(source: Eurostat, own calculations)

The situation of emissions of nitrogen oxides is more interesting. A final regression with a quadratic function was used that corresponds to the theoretical shape of the EKC:

$$
z_{i t}=\beta_{1} y_{i t}+\beta_{2} y_{i t}^{2}+\varepsilon_{i t}
$$

where:

$z_{i t} \quad$ - yearly $\mathrm{NO}_{\mathrm{x}}$ emissions (in $\mathrm{kg}$ ) per capita in country $i$ in year $t$,

$\beta_{i} \quad$ - regression coefficients,

$y_{i t} \quad$ - independent variable average yearly GDP per capita (in PPP) and

$\varepsilon_{i t} \quad$ - error term.

The resulting estimated values of regression coefficients $\beta_{i}$ are

$$
\beta_{1}=+1,32 \cdot 10^{-3}, \beta_{2}=-3,34 \cdot 10^{-8} .
$$

Both coefficients are statistically significant at the 5 $\%$ level, the regression $r^{2}=0,94$. The graph is shown in Figure 12.

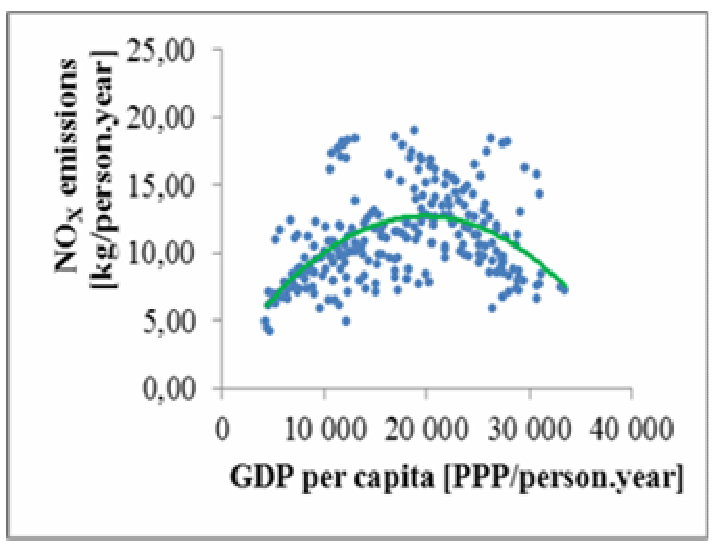

Figure 12: Road transport $N O_{x}$ emissions as function of GDP per capita. (source: Eurostat, own calculations)

A similar decrease of total emissions can be found in the case of $\mathrm{CO}$ emissions from road traffic in the Czech Republic, see Figure 13.

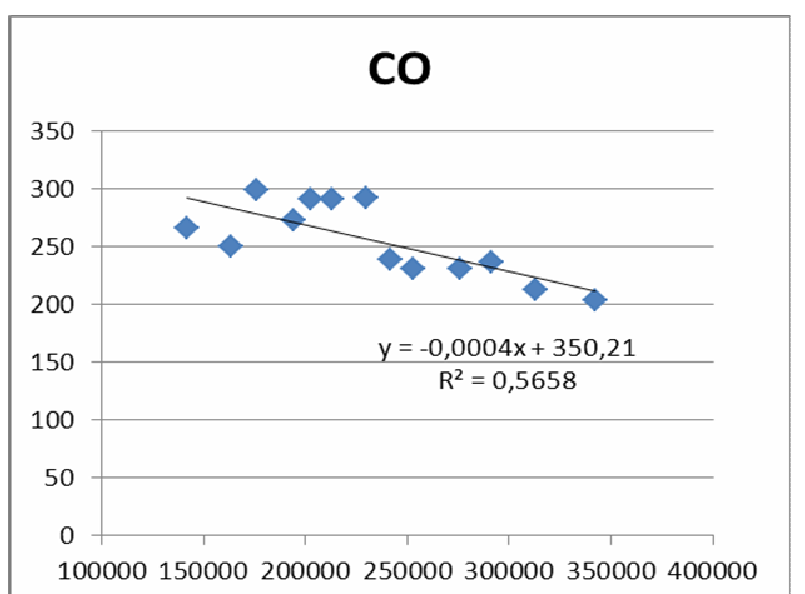

Figure 13: Road transport CO emissions (in thousands of tones yearly) as function of GDP per capita. (source: Eurostat, own calculations) 


\section{ENERGY CONSUMPTION IN ROAD TRANSPORT}

The consumption of energy in road transportation (in the same group of countries) is almost proportional to GDP per capita, as shown in Figure 14.

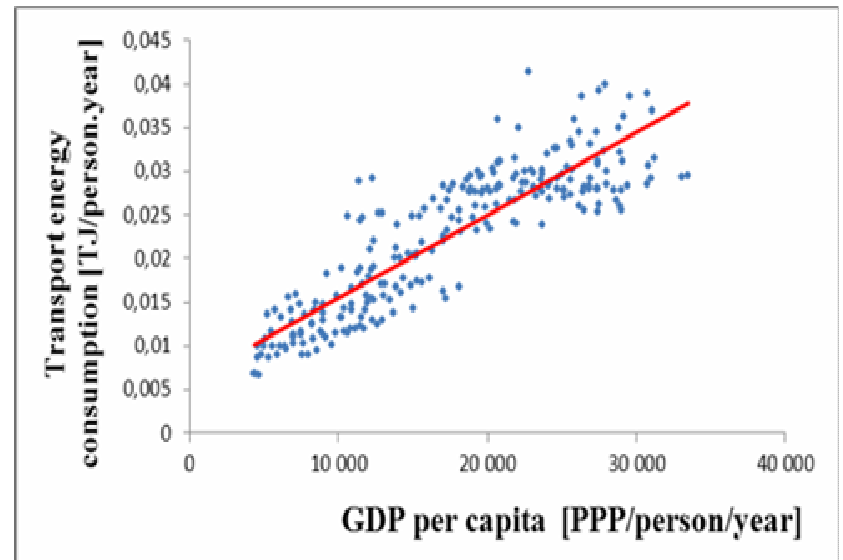

Figure 14: Road transport energy consumption as function of GDP per capita.

(source: Eurostat, own calculations)

The energy consumption (e.g. in road transport) per capita can be expressed as follows:

$$
\frac{E}{P}=\frac{E}{Y} \cdot \frac{Y}{P}=\frac{E}{Y} \cdot y=\rho \cdot y
$$

where:

$E \quad$ - energy consumption per capita,

$P$ - population,

$Y$ - GDP,

$y \quad$ - GDP per capita and

$\rho \quad$ - road transport energy intensity of GDP.

It means that the proportion of energy consumption in road transport to GDP (road transport energy intensity of GDP $\rho$ ) is almost constant.

The emissions per capita can be then expressed as follows (Ř́ha and Honců, 2012):

$$
\frac{X}{P}=\frac{X}{E} \cdot \frac{E}{P}=e \cdot \rho \cdot y
$$

where:

$X \quad$ - total emission,

$P \quad$ - population,

$E \quad$ - road transport energy consumption,

$e \quad-$ emission factor of transport energy consumption,

$\rho \quad$ - road transport energy intensity of GDP and

$y \quad$ - GDP per capita.
Thus we must conclude that the decrease of emissions per capita can be explained only by the decrease of emission factors that means mainly by the more strict emission standards for vehicle producers (EURO 1-6) and emission controls of vehicles. So other relevant important factors as vehicles with lower fuel consumption rates, better logistics and transport technologies etc. are probably not to contribute at the total to this decrease, because the road transport energy intensity of GDP seems to be constant.

\section{DISCUSSION}

For deeper insight we can go on in "chaining" in the form of equation 7 according to the scheme displayed in

$$
\frac{X}{P}=\frac{X}{E} \cdot \frac{E}{T} \cdot \frac{T}{O} \cdot \frac{O}{Y} \cdot y
$$

where:

$X$ - total emissions,

$P$ - population,

$E$ - transport energy consumption,

$T$ - traffic output [vehicle.km],

$O$ - transport output [tkm],

$Y \quad-$ GDP and

$y \quad$ - GDP per capita.

It shows the causal chain of emission production from transport. The economic activity like production generates transport needs that are satisfied by traffic. Traffic needs energy and this (mainly combustion) process generates exhaust emissions.

Every particular fraction in equation 8 represents a stage of emission generating process from Figure 15. Let us comment every stage in the following points:

1. The wealth measured by the (real) individual income represented by GDP per capita naturally generates the need for production (in the general sense, including all economic activities like trade and services as well as free time activities).

2. The various types of economic activity generate needs for transport. E.g. more wealth implies higher free time activities connected with higher car and air transport use. Deeper labour division increases the need for transport; on the other side e.g. cost optimization can lead to closure of some less effective plants generating transport needs.

3. The transport can be realized with different 
needs for traffic dependent on various logistic and transport technologies, e.g. better use of road vehicles can reduce empty running.

4. The transport can often be realized by competing traffic modes with different relative energy consumption, e.g. road and rail traffic. For a certain traffic output, the relative energy intensity of the traffic influences the energy consumption. The overall trend is higher energy efficiency (fastened by the growing oil price), modern turbocharged motors have been lowering the consumption rates, but in some cases (e.g. SUV cars) goes the development in the opposite direction, towards bigger and heavier vehicles.

5. The emission factors of transport energy consumption result in final emissions. There are big differences among modes and types of propulsion. The introduction of European emissions standards EURO 1-6 has been decreasing emissions as well as the development of alternative fuels (LPG, CNG). Electromobility still remains problem, but hybrid technologies have been fast developing.

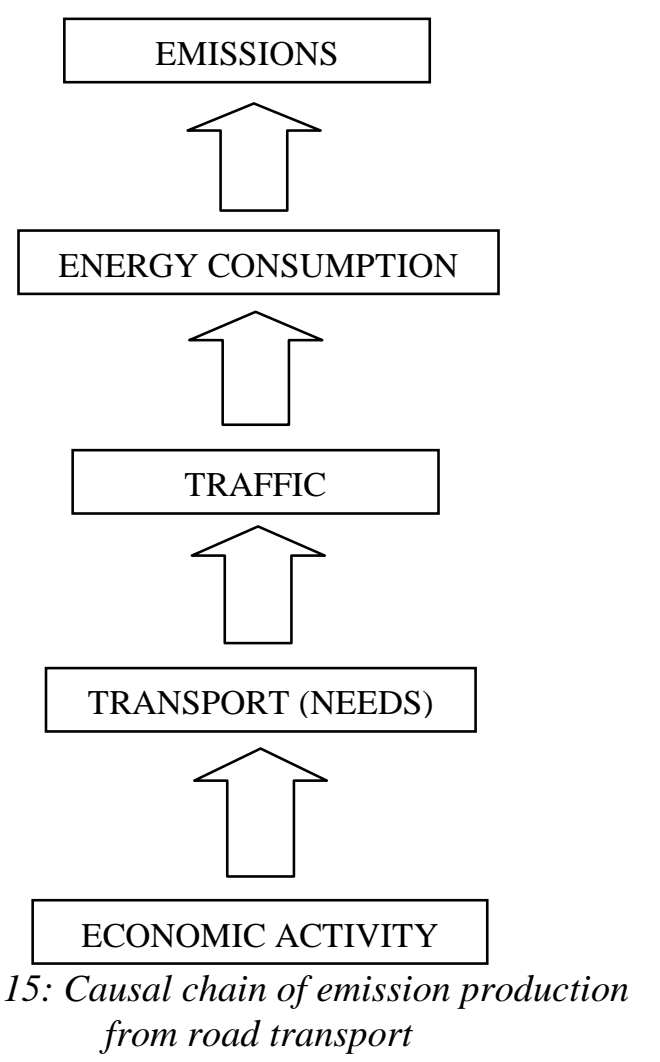

Every stage of this emission generating process is important and should be researched what is our proposal for further work.

\section{CONCLUSION}

The main goal of this paper was to show the importance of the transport for the mankind with respect to its negative externalities in form of e. g. exhaust emissions. The transportation has an important influence on the national economy and on the creation of national wealth. As the best example we can mention industrial revolution, that by supplying of production possibilities forced at the same time the higher efficiency of the transport system (as for the transport means, transport infrastructure or the use of other energy resources). The transportation system strongly influences the economy, the environment as well as the human life quality. The economy with high level of labor division requires efficient logistics and transport system, but it needs increasing transport capacity and impacts more the environment and power supply of the country. It is a proved fact that countries with more liberal economy are economically stronger (the relation between the index of economic freedom and the gross domestic product).

The presented data from the Czech Republic as well from some European countries show that for carbon dioxide the environmental Kuznets curve is not valid. But in the case of the emissions of nitrogen oxides (and some other pollutants), our findings are that their emissions per capita from road transport decrease with the growing wealth of society (expressed by the GDP per capita), i.e. the environmental Kuznets curve could be valid for these type of emissions from road transport. According to our simple analysis the explanation could be only the successful control of emissions, e.g. by the EURO standards and (regular compulsory) emission controls of vehicles. Other important factors like lower consumption vehicles, better transport technologies etc. seem not to contribute at the total to this decrease, because the road transport energy intensity of GDP seems to be constant. However, the problem is more complicated and needs further work.

\section{REFERENCES}

Bhattarai, M., Vijayaraghavan, M., \& Yandle, B. (2004). Environmental Kuznets Curves, A Rewiev of Findings, Methods and Policy Implications Research Study 02-1: PERC.

Cílek, V., \& Kašík, M. (2008). Nejistý plamen. Praha: Dokořán.

Duchoň, B. (2010). Energy and Transport System, Energy Crisis: "Reality and Myth" Application of 
Advanced Technologies in Transportation (pp. 201-210). Athens: National Technical University

Faifrová, V., \& Tichý, J. (2012). Externí náklady dopravního systému. Silnice železnice, 7(1), 6163.

Grossman, G. M., \& Krueger, A. B. (1995). Economic Growth and the Environment. The Quarterly Journal of Economics, 110(2), 353-377.

Kaika, D., \& Zervas, E. (2011). Searching for an Environmental Kuznets Curve (EKC)-pattern for $\mathrm{CO} 2$ emissions Recent Researches in Energy, Environment and Landscape Architecture (pp. 1924): World Scientific and Engineering Academy and Society (WSEAS).

Kuznets, S. (1955, March). Economic Growth and Income Inequality. The American Economic Review, 45(1), 1-28.

Ř́ha, Z., Duchoň, B., \& Faifrová, V. (2011). Energetics, Security and Sustainable Development of Cities. In N. Mastorakis, V. Mladenov, C. M. TraviesoGonzalez \& M. Kohler (Eds.), MMES'11/DEEE'11/COMATIA'11 (pp. 245-250): World Scientific and Engineering Academy and Society (WSEAS).

Ř́ha, Z., \& Honců, M. (2012). Environmental Kuznets Curve in Road Transport Models and Methods in
Applied Science (pp. 180-182): World Scientific and Engineering Academy and Society (WSEAS).

Ř́ha, Z., Jírová, V., \& Honců, M. (2011). Oil Price Analysis Mathematical Models and Methods in Modern Science (pp. 66-70): World Scientific and Engineering Academy and Society (WSEAS).

Smith, A. (2005). An Inquiry into the Nature and Causes of the Wealth of Nations Electronic Classics Series, J. Manis (Ed.) Retrieved from http://www2.hn.psu.edu/faculty/jmanis/adamsmith/wealth-nations.pdf

Veenhoven, R. (2000). The Four Qualities of Life. Ordering concepts and measures of the good life. Journal of Happiness Studies 1(1), 1-39.

\section{ACKNOWLEDGEMENT}

This paper originated as a part of a CTU in Prague, Faculty of Transportation Sciences research project on Design and Operation Networks - Optimization Methods Development (MSM: 6840770043), financed by the Ministry of Education, Youth and Sports of CR. 